\title{
Sexual and Violent Imagery in Movie Previews: Effects on Viewers' Perceptions and Anticipated Enjoyment
}

\author{
Mary Beth Oliver, Sriram Kalyanaraman, Chad Mahood, \\ and Srividya Ramasubramanian
}

Two experiments were conducted to explore the contributions of sexual and violent images contained in movie previews on viewers' anticipated perceptions and enjoyment of previewed films. In neither study were portrayals of sex or violence directly associated with greater anticipated enjoyment. However, both studies provided evidence that sexual and violent portrayals may indirectly enhance viewers' enjoyment via perceptions of heightened suspense (Study 1) or heightened humor (Study 2). These results are discussed in terms of viewers' responses to media images of sexuality and violence, and the importance of these portrayals in the marketing of motion pictures.

Television programs, movies, video games, and the Internet all provide consumers with a multitude of entertaining diversions, with competition for viewers' attention arguably at an all-time high. In terms of motion picture entertainment specifically, the importance of media promotion is evidenced in terms of the sheer amount of money spent on movie marketing. In 2004, member companies of the Motion Picture Association of America spent an average of $\$ 30$ million per film on advertising (MPAA Research Development, 2005). Research concerning the role of motion picture promotion on viewers' preferences also supports the notion that movie previews play an important role in entertainment-selection decisions. For example, Faber and $\mathrm{O}^{\prime} \mathrm{Guinn}$ (1984) found that consumers rated movie trailers as more useful, important, and influ-

Mary Beth Oliver (Ph.D., University of Wisconsin, Madison) is a Professor in the Department of Film/Video \& Media Studies at Penn State University. Her research interests include media effects, psychology of entertainment, and media and social cognition.

Sriram "Sri" Kalyanaraman (Ph.D., Penn State University) is an Assistant Professor at UNC's School of Journalism and Mass Communication. His research interests primarily focus on the psychology of new media, and media effects of sexual, violent, and persuasive health messages.

Chad Mahood (Ph.D., University of California, Santa Barbara) is an Assistant Professor in the School of Communication at The Ohio State University. His research interests include the effects of television, film, and video games.

Srividya Ramasubramanian (Ph.D., Penn State University) is an Assistant Professor in the Department of Communication at Texas A\&M University. Her research interests include media effects and stereotyping processes. 
ential sources of information than any other type of media or interpersonal source with regard to their movie selections.

With the importance of movie promotion resulting in what is an arguable "glut" of movie previews, what types of portrayals succeed in making movies appealing to viewers, or at least making them more appealing than other movies that are also promoted? At first glance, the answer to this question may seem obvious: Movie previews contain content that reflects what one can expect to encounter when viewing the actual motion picture. However, anecdotal evidence suggests that producers of movie previews also typically attempt to appeal to a teenage demographic, and, as such, tend to emphasize what this demographic is thought to enjoy-namely sexual and violent portrayals. As one movie marketer explained, "The objective of nearly every movie trailer is to get teenage boys' butts into seats ... And that means going for as much violence and sex as you can jam into $21 / 2$ minutes" (Streisand, 1999, p. 57). Such statements are consistent with the Federal Trade Commission's (FTC) landmark report (2000) which argued that movie producers use these elements (particularly violence) to target specific audiences and to presumably enhance audience interest. They are also consonant with Oliver and Kalyanaraman's (2002) content analysis of movie previews reporting that approximately $76 \%$ of the previews in their sample featured at least one act of aggression (with an average of 2.5 aggressive acts per minute), and that $56 \%$ of the previews featured at least one sexual scene (with an average of 1.5 sexual scenes per minute).

Given the prevalence of motion picture marketing and the important role that promotion is thought to play in viewers' selection of entertainment, the purpose of this research was to examine the influence of specific portrayals in movie previews on viewers' perceptions. Namely, this research explored the effects of sexual and violent images in previews on viewers' perceptions-and anticipated enjoyment-of the film.

\section{Explanations for the Role of Violent and Sexual Content in Anticipated Enjoyment}

It would appear that industry conjecture concerning viewer enjoyment, as well as content analytic research, imply that sexuality and particularly violence may play important roles in viewers' selection and anticipated enjoyment of motion picture entertainment, though whether or not this conjecture is correct and the reasons for why it may be effective are unclear at this point. Perhaps the most straightforward explanation for the possible effectiveness of sex and violence in movie trailers is that such portrayals accurately depict what movie-goers will see and, more importantly, want to see in full-length feature films. The idea that at least some individuals find images of violence and sexuality inherently appealing or gratifying has received an abundance of research attention with a variety of explanations offered for the gratifications that viewers may obtain. Among these explanations are that sexual and violent portrayals 
offer viewers the opportunity for catharsis or sexual release (e.g., Feshback \& Singer, 1971), that violent portrayals provide viewers with the opportunity to confront their own anxieties in safe environments (e.g., Goldstein, 1986), or that individuals have a natural (or sometimes morbid) curiosity about these types of media images (e.g., Aluja-Fabregat, 2000; Zuckerman \& Litle, 1986).

Of course, the argument that violence and sexuality are effective selling tools in movie promotion because people simply enjoy these types of portrayals is far from a satisfying explanation. If sex and violence were the primary depictions of interest to audiences, then the movie landscape would presumably focus exclusively on these types of portrayals. However, it's clear that viewers are interested in a variety of portrayals and story lines (e.g., drama, comedy), and yet violence and, to a lesser extent, sexuality, are employed as marketing tools across a diversity of genres nevertheless. Consequently, alternative theoretical mechanisms are needed to help understand how (and if) violence and sex may effectively function as a means of attracting viewers to a diverse array of motion picture genres.

Research on disposition theory provides one useful framework for understanding how violence in particular may serve to boost audience gratification (e.g., Bryant \& Miron, 2002; Raney, 2003; Raney \& Bryant, 2002; Zillmann \& Bryant, 1994; Zillmann \& Cantor, 1977). In discussing media characteristics that make for "good drama," Zillmann, Bryant, and their colleagues are quick to point out that a crucial ingredient appears to be the depiction of conflict and its acceptable resolution (Bryant \& Miron, 2002; Zillmann \& Cantor, 1977). Although the notion of "conflict" may be conceptualized in a variety of ways, dramatic conflict is broadly defined as typically involving a clash between characters, which could occur in a variety of genres such as comedy, suspense, drama, etc. Across these types of entertainment fare, viewers are thought to experience the greatest level of gratification when protagonists experience positive outcomes and/or when disliked characters experience failure or defeat, whereas enjoyment is predicted to be hampered by the portrayal of protagonists who succumb to failure or antagonists who are depicted as "unjustly" rewarded. In short, disposition theory predicts that viewer enjoyment depends on the depiction of dramatic conflict, viewers' dispositions toward the parties involved in the conflict, and the ultimate outcomes that the parties experience. What this theory implies, therefore, is that the depiction of conflict is a necessary (though not sufficient) condition for viewer enjoyment. As Zillmann (1996) noted:

The clash of two or more antagonistic forces is viewed as a basic, necessary condition for drama. Any and every dramatic situation is said to arise from such conflict, and it is explicated or implied that drama cannot exist without the display of conflicts and crises in one form or another (p. 201).

Disposition theory has been applied to a variety of genres and media depictions, including crime dramas (Raney \& Bryant, 2002), sports (Zillmann, Bryant, \& Sapolsky, 1989), suspense (Oliver, 1993; Zillmann, 1980, 1996), humor (King, 2003; Zillmann, 
2000), and news (Zillmann, Taylor, \& Lewis, 1998), among others. In general, this line of research suggests that violence can play an important role in viewer enjoyment by enhancing the degree of perceived conflict or by depicting an outcome that is seen as appropriate or "just" (e.g., the violent punishment of a villainous character). For example, in the context of sports, Bryant (1989) argued that heightened perceived conflict is one explanation for viewers' enjoyment of violent or rough play: "The more violent the contest, the clearer the indication that the battle is being bitterly fought, and the greater the drama and the viewers' enjoyment" (p. 281). Likewise, in applying disposition theory to the context of humor, Zillmann and Bryant (1991) argued that aggression and hostility play a central role in many comedic offerings in which individuals are routinely "debased, demeaned, disparaged, ridiculed, humiliated, or otherwise subjected to undesirable experiences short of truly grievous harm" (p. 270).

It is interesting to note that research on disposition theory does not suggest that violence per se is necessarily enjoyed by viewers, but rather what violence may imply about dramatic conflict and its resolution. Consequently, this interpretation may help explain why portrayals of violence may not always enhance viewer enjoyment, and particularly if they are not perceived as contributing in a meaningful way to some narrative or story line or if other narrative elements are successful in creating the dramatic conflict intended (e.g., Berry, Gray, \& Donnerstein, 1999; Hansen \& Hansen, 1990; Sparks, Sherry, \& Lubsen, 2005; Zillmann \& Mundorf, 1987). What might this mean, then, for the role of violence in motion picture promotion? Given that movie trailers have only an abbreviated amount of time in which to overview the plot of a film and to pique viewers' interest, violent content may effectively function as a quick and unambiguous indicator that the film will contain dramatic conflict-be it conflict in the form of suspense, conflict in the form of romantic entanglements, or conflict in the form of humorous clashes. More protracted depictions of dramatic conflict such as arguments, chase scenes, or witty banter that may be actually featured in the film are not only arguably improbable to include in 2-minute trailers, but they may further not "translate" well to global movie-marketing contexts (Gerbner, 1999). One implication of this interpretation is that violence in previews may not necessarily increase anticipated enjoyment because viewers anticipate more violence, but rather because violence increases anticipation associated with the type of dramatic conflict expected (e.g., suspense, humor).

Although a substantial amount of research has explored the role of media violence in enhancing dramatic narrative, much less attention has been given to how depictions of sexuality may function in regard to viewers' perceptions and enjoyment. Although noting that sexual depictions may be enjoyable in and of themselves and that romantic and sexual themes may be central to many movie plots, the issue of how sexual portrayals in movie promotion affect expectations and anticipated enjoyment is unclear at this point. At a most basic level, it seems reasonable to suggest that both violent and sexual portrayals may effectively serve to increase viewer attentionthereby making the previewed movie more salient or memorable. However, research on the arousing potential of media content suggests that these types of images may 
also serve to intensify additional perceptions that may be seemingly unrelated to aggression or sexuality.

Specifically, the excitation transfer framework suggests that arousal elicited from one instigating stimulus can serve to heighten emotional responses to-and perceptions of-concurrent or subsequent stimuli occurring in close temporal proximity (Bryant \& Miron, 2003; Zillmann, 1971; Zillmann, 1984; Zillmann, Hay, \& Bryant, 1975). Further, given the nonspecific nature of arousal, the valence associated with an instigating stimulus need not be the same as the valence associated with the subsequent or co-occurring stimulus. For example, arousal elicited from frightening stimuli may serve to intensify subsequently experienced feelings of joy or relief, arousal from exposure to sexuality may serve to intensify feelings of hostility, or arousal from something as simple as increased exercise can serve to intensify perceptions of the aesthetic value of erotic entertainment. The importance of excitation transfer on viewers' perceptions of media content has been demonstrated in a variety of genres, including suspense (Zillmann, 1980), horror (Oliver, 1994), erotic materials (Cantor, Zillmann, \& Bryant, 1975), humor (Cantor, Bryant, \& Zillmann, 1974), music (Cantor \& Zillmann, 1973), and advertising (Mattes \& Cantor, 1982). Applied to the context of movie promotions, this reasoning suggests that although violent and/or sexual portrayals may be attention-getting and arousing in their own right, these types of depictions may also function to intensify responses to other aspects of media depictions occurring in close temporal proximity (e.g., humorous content, tragic portrayals, suspenseful scenes). Ultimately, insofar as these other perceptions are an expected and desired reaction to the plot (e.g., humor in response to a comedy), sexual and violent portrayals may lead indirectly to greater anticipated enjoyment.

\section{Present Research}

In summary, sexual and violent images are staples in movie promotion, with their prevalence implying that they are commonly used as a means of luring viewers to the screen. A review of existing literatures and theoretical perspectives on viewers' responses suggests two hypotheses. On the one hand, portrayals of sexuality and violence may be inherently enjoyable to viewers, suggesting that the inclusion of such images should be directly related to favorable evaluations:

\footnotetext{
$\mathrm{H}_{1 \mathrm{a}}$ :The inclusion of sexual and/or violent images in a movie preview will be directly associated with anticipated enjoyment of the previewed film.
}

In contrast, prior theorizing on viewers' responses to these depictions in entertainment suggests that these types of portrayals may function in ways that are broader than simply appealing to viewers' curiosity about violence and sex per se. That is, violence and sexuality in movie promotion may function as effective selling tools not so much because they affect viewers' expectations about seeing these specific types of 
images in the full-length film, but because they serve to heighten expectations that are more proximate precursors to anticipated enjoyment.

\footnotetext{
$\mathrm{H}_{1 \mathrm{~b}}$ :The inclusion of sexual and/or violent images in movie previews will be indirectly associated with anticipated enjoyment via perceptions of other film characteristics (e.g., suspense, humor).
}

To examine the scope of these competing hypotheses across variations that may be attributable only to differences associated with any specific genre, two studies were conducted-Study 1 in the context of suspense, and Study 2 in the context of comedy. Audience responses to suspense and to comedy were clearly expected to differ, with previews for suspense predicted to elicit perceptions of thrills, and previews for comedy predicted to elicit perceptions of humor. However, the exploration of two genres allowed for the examination of the theorized role of sexual and violent images in influencing audience perceptions in ways that may ultimately lead to increased anticipated enjoyment.

\section{Study 1}

\section{Method}

Participants. One-hundred and eight undergraduate students $(N=108)$ participated in the experiment in exchange for a nominal amount of extra credit. ${ }^{1}$ These participants consisted of 68 females and 40 males who ranged in age from 19 to 33 years, $M=21.38, S D=2.14$.

Design and Procedures. This study employed a $2 \times 2$ between-subjects experimental design in which participants were randomly assigned to view a preview for a movie that varied the presence of sexual images (present, absent) and violent images (present, absent). ${ }^{2}$ Study sessions were conducted by trained graduate students in a quiet room located in a building adjacent to campus. Participants in small groups of one to four individuals viewed the movie preview on a large-projection video screen that was approximately 4 feet in height, with individuals seated at a distance that would allow for comfortable viewing (i.e., approximately 15-20 feet away from the screen).

Stimulus Materials. The trailer employed in this study was a 30-second preview for a foreign-language film that could best be described as a suspense-thriller. ${ }^{3}$ The English-language narration included in the preview was constant across the four experimental conditions, with the narrator using the words "suspenseful" and "thriller" to describe the film. The video images consisted of a montage of semantically unrelated rapidly changing scenes from the movie. These images were edited by using the 
original preview as the base and inserting video footage taken from the full-length motion picture into the preview so as to manipulate the presence or absence of sexual and/or violent images. The manipulation of sexual images involved the inclusion of a total of five scenes accounting for 12 of the 30 seconds. These scenes included a man and a woman kissing, a woman pulling up her skirt and sitting on a man's lap, and a man unclothed (though covered by a blanket) in bed, etc. The manipulation of the violent images involved the inclusion of a total of five scenes accounting for 9 of the 30 seconds. These scenes included a man whose face had been bloodied, two men pushing and shoving another man, a man pointing a gun at another individual, etc.

Measures. Immediately after viewing the preview, participants completed a questionnaire asking them to indicate their perceptions of the film based on what was seen in the preview. The first section of the questionnaire presented a series of adjectives (e.g., enjoyable, violent, boring, etc.), instructing participants to indicate the extent to which each adjective was descriptive of their anticipated perceptions of the film using scales ranging from 1 (not at all) to 7 (very much). The second section asked participants to indicate their overall interest in viewing and their likelihood of selecting to view the film in a variety of venues (e.g., on video, in the theater, etc.) on scales ranging from 1 (not at all) to 7 (very much).

An exploratory factor analysis was conducted using principal components extraction and varimax rotation to reduce the number of items into subscales. One item (ratings of funny) was dropped because it was the single variable loading on a given factor, and two additional items (ratings of suspenseful and ratings of thrilling) were dropped because they cross-loaded across factors. However, these two items were strongly correlated $(r=.71, p<.001)$ and were consequently averaged into a single scale labeled "anticipated suspense" for use in subsequent analyses $(M=4.90 ; S D=$ 1.26). The factor analysis of the remaining items revealed three factors accounting for $70.60 \%$ of the variance. (A factor analysis employing an oblique rotation yielded the same factor structure). The first factor labeled "anticipated enjoyment" consisted of ratings of enjoyable, exciting, interesting, boring (reverse coded), as well as overall interest in viewing and the likelihood of selecting the movie to view on video, on pay television, and in the theater $(M=4.11 ; S D=1.34$, Cronbach's $\alpha=.94)$. The second factor labeled "anticipated violence" consisted of ratings of scary, violent, disturbing, and aggressive $(M=4.15 ; S D=1.20$, Cronbach's $\alpha=.79)$. The final factor labeled "anticipated sexuality" consisted of ratings of erotic, sexually explicit, and arousing $(M=4.13 ; S D=1.45$, Cronbach's $\alpha=.81)$.

\section{Results}

Manipulation Checks. To examine the extent to which the inclusion of sex and violence affected participants' expectations of sexuality and violence in the film, two general linear model analyses of variance (ANOVAs) were conducted on anticipated 
sexuality and violence, employing sex (present/absent) and violence (present/absent) in the preview as the independent variables (IVs). The analysis of anticipated sexuality revealed a main effect for sex, with anticipated sexuality scores higher in the sex-present condition $(M=4.97, S E=.16)$ than in the sex-absent condition $(M=3.28$, $S E=.16), F(1,104)=53.91, p<.001, \eta_{p}^{2}=.34$. No other significant effects were obtained. Similarly, the analysis of anticipated violence revealed a main effect for violence, with anticipated violence scores higher in the violence-present condition $(M=$ $4.41, S E=.16)$ than in the violence-absent condition $(M=3.91, S E=.16), F(1,104)=$ 4.69, $p<.05, \eta_{p}^{2}=.04$. No other significant effects were obtained.

Direct Effects of Sex and Violence on Anticipated Enjoyment. To examine the effects of sex and violence on anticipated enjoyment of the film, a general linear model ANOVA was conducted on enjoyment ratings, using sex and violence in the preview as IVs. Contrary to Hypothesis $\mathrm{H}_{1 \mathrm{a}}$, neither the main effects nor the interaction effects were statistically significant (all $F_{\mathrm{S}}<1$ ).

Effects of Sex and Violence on Expectations Associated with Anticipated Enjoyment. Subsequent analysis were conducted to further explore the relationship between images of sexuality and violence in the preview, resulting variations in expectations of what the film would be like, and, ultimately, anticipated enjoyment. Specifically, a path analysis was conducted to explore how images of sexuality and violence contribute to anticipated sexuality and violence in the full-length feature, and how these perceptions were related to anticipated suspense and enjoyment. In this analysis, sexuality and violence in the preview were treated as exogenous variables, and anticipated enjoyment was employed as the final variable in the path. The initial model included paths between all significant correlations, with the final model reflecting only those paths that were significant at $p<.05$ (cf. Segrin \& Nabi, 2002).

Figure 1 contains the final model in this analysis, with all paths reporting standardized coefficients. This model is associated with $\chi^{2}=9.30, d f=9, p=.41$, suggesting a good fit. Other indicators of fit suggested similar conclusions, $\chi^{2} / d f$ ratio $=1.03 ; \mathrm{NFI}=$ .96 ; RMSEA = .02 (Arbuckle, 1996; Byrne, 2001; Maruyama, 1997; Schumacker \& Lomax, 1996). Consistent with Hypothesis $\mathrm{H}_{1 \mathrm{~b}}$, this model illustrates that images of sexuality and violence in the movie preview were associated with increases in anticipated enjoyment, though the path from these variables was indirect. Specifically, images of sexuality were associated with greater anticipated sexuality in the film ( $\beta=$ $.56)$, and images of violence were associated with greater anticipated violence in the film $(\beta=.22)$. Both of these variables, in turn, were associated with higher levels of anticipated suspense (anticipated sexuality, $\beta=.19$; anticipated violence, $\beta=.60$ ), which were associated with greater anticipated enjoyment $(\beta=.72)$. This model also showed that higher scores on anticipated violence were associated with higher scores on anticipated sexuality $(\beta=.52)$. Bootstrapping of the indirect effects of images in the preview on anticipated enjoyment revealed significant indirect effects for both violent images $(\beta=.09, p<.05)$ and sexual images $(\beta=.07, p<.05)$. 


\section{Figure 1}

Path Analysis of Relationships between Sexuality and Violence and Anticipated Perceptions in Study 1

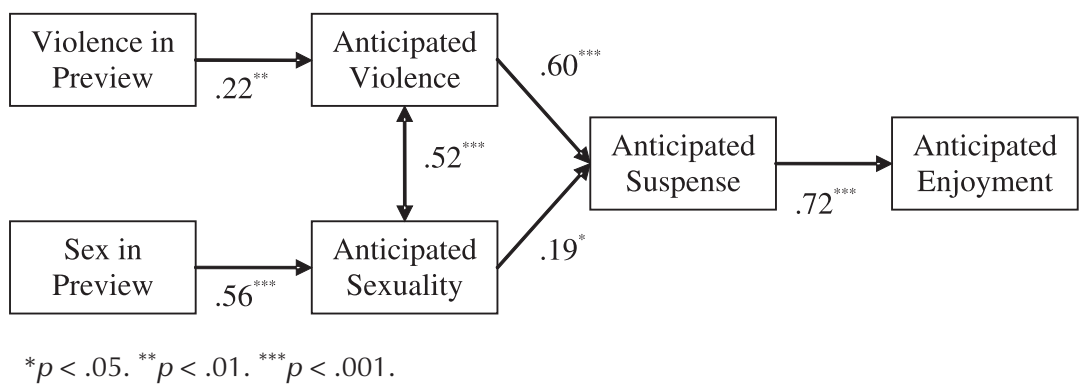

\section{Discussion}

The results of Study 1 suggest that although the inclusion of sex and violence in a movie preview affects viewers' anticipation of seeing sex and violence in the actual motion picture, effects on increasing enjoyment are not direct. Rather, sex and violence appear to affect anticipated enjoyment indirectly by intensifying anticipation of suspense in the film. However, because only one type of film was examined, perhaps suspense thrillers are unique in juxtaposing sexual and violent portrayals in the depiction of frightening scenes (see Cowan \& O'Brien, 1990; Linz \& Donnerstein, 1994). If this speculation is correct, then the results of this study may suggest that sexual and/or violent images in movie previews may be effective at ultimately increasing anticipated enjoyment, but only for a limited number of genres. To explore whether the findings in this study are unique to only certain types of films, a second experiment was conducted using the same procedures but examining a distinctly different genre.

\section{Study 2}

\section{Method}

Participants. One-hundred and thirty-five $(N=135)$ undergraduate students (100 females; 35 males) participated in the experiment in exchange for a nominal amount of extra credit. Eighty-six of these participants were enrolled at a large West Coast university, and 49 were enrolled at a large northeastern university. ${ }^{4}$ Participants ranged in age from 18 to 26 years, $M=19.93, S D=1.54$.

Design and Procedures. This study employed a $2 \times 2$ between-subjects experimental design in which participants were randomly assigned to view a preview for a 
movie that varied the presence of sexual images (present, absent) and violent images (present, absent). ${ }^{5}$ Participants viewed the preview on a large-projection video screen that was approximately 4 feet in height, with individuals seated at a distance that would allow for comfortable viewing (i.e., approximately 15-20 feet away from the screen).

Stimulus Materials. The trailer employed in this study was a 60-second preview for a foreign-language comedy. The English-language narration included in the preview was constant across the four experimental conditions, with the narrator describing the movie as "funny" and as "a breezy charmer." The video images consisted of a montage of semantically unrelated rapidly changing scenes from the movie. These scenes were edited by using the original preview as the base and inserting video footage taken from the full-length motion picture into the preview so as to manipulate the presence or absence of sexual and/or violent images. The manipulation of sexual images involved the inclusion a total of five scenes accounting for 15 of the 60 seconds. These scenes included a man and a woman kissing, a woman pouring water over her body in a seductive manner, a man and a woman making love (though full nudity was not seen), etc. The manipulation of the violent images involved the inclusion of six scenes accounting for 15 of the 60 seconds. These scenes included a man smashing two other men's heads together, a man holding a gun to another man's head, a woman punching a man in the face, etc.

Measures. Immediately after viewing, participants indicated their perceptions of the film based on what was seen in the preview. The first section of the questionnaire presented a series of adjectives, instructing participants to indicate the extent to which each adjective was descriptive of their anticipated perceptions of the film on scales ranging from 1 (not at all) to 7 (very much). The second section asked respondents to indicate their overall interest in viewing and their likelihood of selecting to view the film in a variety of venues on scales ranging from 1 (not at all) to 7 (very much).

An exploratory factor analysis using principal components extraction and varimax rotation resulted in four factors accounting for $74.12 \%$ of the variance. (A factor analysis employing an oblique rotation yielded the same factor structure). The first three factors were the same as those obtained in Study 1: "anticipated enjoyment" $(M=$ 3.00; $S D=1.24$, Cronbach's $\alpha=.92)$, "anticipated sexuality" $(M=3.17 ; S D=1.50$, Cronbach's $\alpha=.85)$, and "anticipated violence" ( $M=1.86 ; S D=0.95$, Cronbach's $\alpha$ $=.79$ ). The final factor, labeled "anticipated humor" consisted of ratings of funny, comical, humorous, and slapstick $(M=3.76 ; S D=1.24$, Cronbach's $\alpha=.86)$.

\section{Results}

Manipulation Checks. To examine the extent to which the inclusion of sex and violence affected participants' perceptions, two general linear model ANOVAs were 
conducted on anticipated sexuality and violence, employing sex (present/absent) and violence (present/absent) in the preview as the IVs. The analysis of anticipated sexuality revealed only a main effect for sex, with anticipated sexuality scores higher in the sex-present condition $(M=3.88, S E=.17)$ than in the sex-absent condition $(M=2.51$, $S E=.16), F(1,131)=35.23, p<.001, \eta_{p}{ }^{2}=.21$. Similarly, the analysis of anticipated violence revealed only a main effect for violence, with anticipated violence scores higher in the violence-present condition $(M=2.31, S E=.11)$ than in the violenceabsent condition $(M=1.45, S E=.10), F(1,131)=34.40, p<.001, \eta_{p}^{2}=.21$.

Direct Effects of Sex and Violence on Anticipated Enjoyment. To examine the effects of sex and violence on participants' anticipated enjoyment of the film, a general linear model ANOVA was conducted on enjoyment ratings, using sex and violence in the preview as IVs. This analysis revealed a main effect for violence, $F(1,131)=$ $11.99, p<.001, \eta_{p}^{2}=.08$, with participants reporting higher enjoyment scores for the previews featuring violence $(M=3.36, S E=.14)$ than for those previews not featuring violence $(M=2.66, S E=.14)$. However, this main effect should be interpreted in light of a Sex $\times$ Violence interaction that was also obtained, $F(1,131)=5.45, p<.05, \eta_{p}^{2}=$ .04 . This interaction occurred because higher ratings of anticipated enjoyment were more pronounced when sexuality was absent (violent previews: $M=3.65, S E=.19$; nonviolent previews: $M=2.51, S E=.19$ ) than when it was present (violent previews: $M=3.03, S E=.20$; nonviolent previews: $M=2.81, S E=.20$ ). Consequently, this study revealed only partial support for $\mathrm{H}_{1 \mathrm{a}}$.

Effects of Sex and Violence on Expectations Associated with Anticipated Enjoyment. A path analysis was conducted to explore how images of sexuality and violence contributed to anticipated sexuality and violence in the full-length feature, and how these perceptions were related to anticipated humor and enjoyment. The same procedures that were employed in Study 1 were employed in this analysis.

Figure 2 contains the final model in this analysis, with all paths reporting standardized coefficients. This model is associated with $\chi^{2}=13.35, d f=7, p=.07$, suggesting a reasonably good fit. Other indicators of fit suggested similar conclusions, $\chi^{2} / d f$ ratio $=1.91 ; \mathrm{NFI}=.94 ; \mathrm{RMSEA}=.08$ (Arbuckle, 1996; Byrne, 2001; Maruyama, 1997; Schumacker \& Lomax, 1996). This model illustrates that images of sexuality and violence in the movie preview were associated with anticipated enjoyment, though the path from these variables was indirect. Specifically, images of sexuality were associated with greater anticipated sexuality in the film $(\beta=.42)$, and anticipated sexuality was associated with both greater anticipated humor $(\beta=.54)$ and with greater anticipated enjoyment $(\beta=.18)$. Interestingly, however, the direct path from sexual imagery to anticipated humor was negative $(\beta=-.28)$. In terms of violent images, these portrayals were associated with greater anticipated violence $(\beta=.42)$ and with greater anticipated humor $(\beta=.28)$, though the path from anticipated violence to anticipated humor was nonsignificant. Finally, anticipated humor $(\beta=.55)$ was associated with 


\section{Figure 2}

\section{Path Analysis of Relationships between Sexuality and Violence and Anticipated Perceptions in Study 2.}

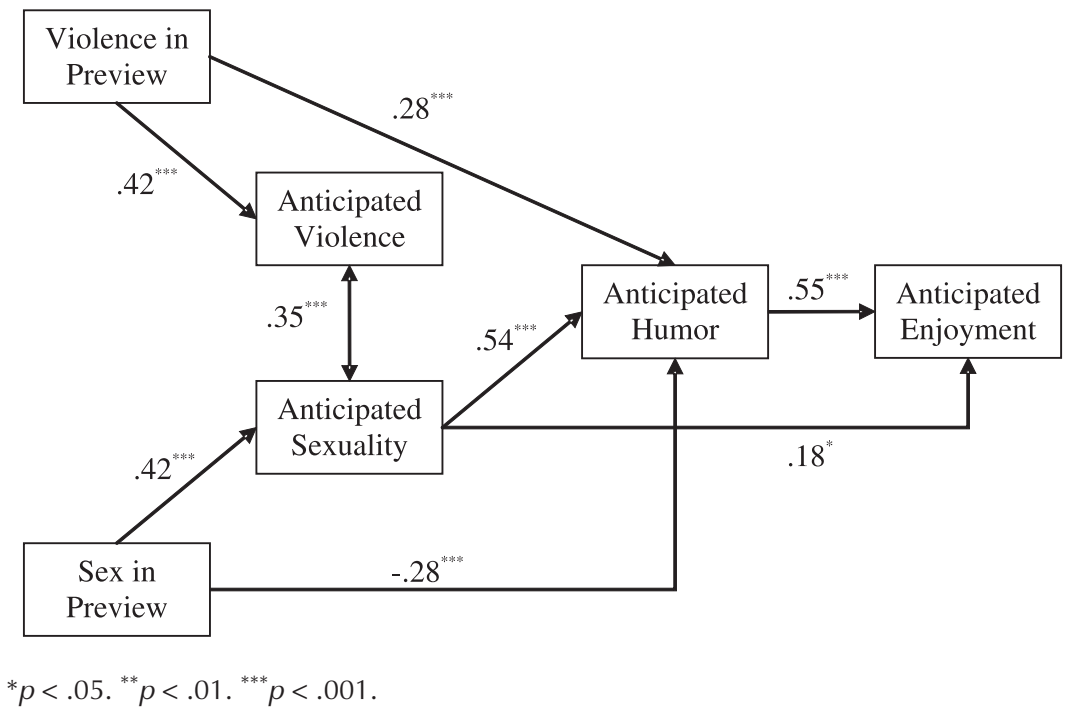

higher ratings of anticipated enjoyment. Bootstrapping of the indirect effects of images in the preview on anticipated enjoyment revealed a significant indirect effect for violent images $(\beta=.16, p<.01)$ but not sexual images $(\beta=.05, n s)$. However, the indirect effect on anticipated enjoyment via anticipated humor was significant $(\beta=.30$, $p<.01)$. These results lend general support for $\mathrm{H}_{1 \mathrm{~b}}$.

\section{Discussion}

The results of Study 2 largely replicate those obtained in the first study, albeit for an alternative genre. Whereas the initial analysis suggested that portrayals of violence served to heighten anticipated enjoyment, the subsequent path analysis demonstrated that this relationship was mediated by anticipated humor. That is, the most noteworthy function of portrayals and perceptions of sexuality and violence were in affecting perceptions of humor, with humor being the strongest, most direct predictor of anticipated enjoyment. Although some differences were observed between the respective models for suspense versus comedy (discussed below), the results of Study 2 suggest that sexuality and violence in movie previews may function in similar ways across different genres. 


\section{General Discussion}

The results of the two studies reported here make an important contribution to the existing literature by offering evidence for the indirect role of sexual and violent imagery in movie marketing in general rather than in the context of only one type of genre. Together, the results of these studies suggest that even a subtle manipulation of sexual or violent content appears to have strong effects on audiences' expectations of what the previewed film will be like.

In examining the particular psychological effects that manifest upon viewing sexual and violent images in a movie preview, the current research revealed that exposure to violence and sex in movie previews led to an increase in anticipated violence and sexuality in the full-length motion picture. That is, the presence of sex and violence in the preview increased perceptions that more sex and violence would be encountered when the actual feature film is seen in its entirety. In this regard, viewers seemed to assume that the content of movie previews is representative of the subject matter depicted in the full-length movie and consequently, they appeared to have used the material portrayed in movie previews as the basis for their thoughts about what to expect from the movie.

In addition, these studies found that, consistent with Hypothesis $1 \mathrm{~b}$, the strongest effects of sex and violence on anticipated enjoyment were indirect, operating primarily to affect viewers' anticipation of suspense or humor, with these variables being the strongest predictors of participants' interest in seeing the previewed film. These results are consistent with both disposition theories of drama and with predictions associated with excitation transfer. Namely, in contrast to Hypothesis 1a, neither of these perspectives implies that viewers necessarily enjoy sex and violence per se, but both of these perspectives suggest that these types of images may serve to intensify perceptions of dramatic conflict that viewers do appear to find gratifying.

Interestingly, both studies also revealed significant positive associations between anticipated violence and anticipated sexuality. Clearly, there are multiple possible interpretations for the presence of such a relationship. One explanation could reside in the excitation transfer framework, which suggests that viewers may be unable to unambiguously attribute their arousal to sexual or violent stimuli (Bryant \& Miron, 2003; Zillmann, 1971, 1998). Alternatively, the connection between perceptions of sex and violence may also be due to the possibility that if participants see more violence, they are more likely to believe that the movie contains more adult portrayals in general, and hence more sexual portrayals as well. An additional explanation for the correlation between these two variables could be that viewers have developed a mental model that associates violence and sexuality within their cognitive framework of what movie previews represent (Roskos-Ewoldsen, Roskos-Ewoldsen, \& Carpentier, 2002), so that the presence of violence "primes" or triggers anticipations of sexuality as well. If participants believe they are viewing a typical "R-rated" film preview, they may then access an R-rated movie schema. This schema would inevitably contain 
thoughts and images relating to both sex and violence. Clearly, these interpretations are speculative at this point, though they suggest that the interrelationships between sex and violence in movie previews are deserving of greater elaboration in subsequent studies. Future research may not only examine the existence and activation of an "R-rated sex and violence schema," but also determine if such a schema carries over to perceptions of sexual-violent connections outside of the realm of entertainment.

With these similarities between the results of the two studies in mind, it is important to note some differences between the models obtained in Study 1 versus Study 2. First, unlike Study 1, Study 2 revealed a direct path from anticipated sexuality to enjoyment that bypassed anticipated humor. In the context of comedy, it appears that anticipation of sexuality-irrespective of whether such anticipations are associated with humor or not-may serve to increase interest and enjoyment. Curiously, this model also showed a negative relationship between portrayals of sex and anticipated humor. However, an examination of the bivariate correlations showed no statistically significant relationship between these two variables, suggesting that anticipated sexuality acted as a suppressor variable in the relationship between sexual portrayals and humor. That is, once perceptions of increased sexuality were statistically accounted for, sexual portrayals seemed to diminish anticipated humor. Therefore, sexual portrayals may function to increase expected humor, but only insofar as they increase anticipated content that is perceived as "erotic" or "arousing" (as was measured here).

Also unlike Study 1, Study 2 found that violence in the previews was directly associated with greater anticipated humor, bypassing participants' perceived violence. Hence, portrayals of aggression appeared to enhance the comedy, but not by increasing viewers' anticipation of aggression or violence. Although these findings warrant further scrutiny, the results obtained here may reflect the notion that violent portrayals serve to increase perceived humor via some alternative mechanism, such as arousal. This interpretation is consistent with prior research showing that participants rated humorous cartoons as funnier if the cartoons followed arousing rather than non-arousing messages (Cantor et al., 1974). Alternatively, an additional interpretation may be that violent portrayals in the context of humor are not perceived as especially harmful or aggressive, but are rather seen as but one example of a type of humor that the viewer may expect to encounter in comedy. This interpretation is consistent with Potter and Warren's (1998) argument that violence in the context of humorous portrayals tends to diminish the perceived seriousness or harmfulness of portrayed aggressive acts (King, 2000; Potter, Pashupati, Pekurny, Hoffman, \& Davis, 2002). Of course, the belief that viewers may perceive aggressive behaviors as humorous should not be understood as implying that violence in comedies is of no concern. In fact, research from a variety of theoretical perspectives suggests that the trivialization of the harmful consequences of violence may be particularly associated with increased likelihood of aggression on the part of the viewer (Bandura, 1983; Jo \& Berkowitz, 1994). 
In answer to the specific question concerning whether sex and violence "sell," the response is that maybe they do, but only indirectly. As can be observed from the path analyses in both studies, the direct paths between sex and violence in movie previews and anticipated enjoyment failed to attain statistical significance. That is, the presence of sex and violence were associated only with intervening variables, with anticipated suspense or humor being the strongest predictors of increased viewer expectations of movie enjoyment. These results suggest that anticipated enjoyment is not so much of a reflection of sexual and violent images in isolation as it is a reflection of perceptions that may result from such images. As such, these results further imply that if some other types of portrayals could be used to increase anticipated humor (e.g., jokes, puns, etc.) or suspense (e.g., eerie music, dark lighting, etc.), then sex and violence may not be required to increase a movie's appeal to viewers. Thus, it appears that sex and violence as such do not sell, but other perceptions about the movie that they trigger (i.e., anticipation about how funny the movie will be) are responsible for attracting viewers.

Even though the results of these studies indicate that sex and violence in movie previews lead to a series of heightened expectations about the movie itself, there are some limitations that deserve attention. First, although two different genres were examined in this research to explore the scope of the resulting models, there obviously exist numerous additional genres not explored, including action adventure, drama, and science fiction, among others. Accordingly, the examination of additional genres would clearly contribute to the robustness of this model. Likewise, employing a sample other than college students would allow for greater generalization. Although college students may be a particularly appropriate demographic to study given their high consumption of entertainment, and movie entertainment specifically, this same sample may be more likely than other age groups to be responsive to violent and sexual portrayals. Therefore, generalizing the results of this research to other populations should be done with caution, and future research may gain from exploring other age ranges and educational levels.

Future research would also benefit from the inclusion of additional variables. For example, the authors suggest that these results are consistent with predictions from an excitation-transfer perspective. However, this argument would clearly be more compelling were physiological data to be employed in addition to self-report measures.

In addition, future research should consider further explorations concerning the manner in which sex and violence are portrayed to determine whether the nature of the portrayals plays a role in viewers' perceptions. For example, given the importance of "just" resolutions in disposition theory's account for audience enjoyment, violent imagery that implies the defeat of a beloved protagonist may serve to dampen viewer interest. Therefore, future research may profitably explore not only the presence and absence of violent and sexual imagery, but also the types of imagery that may lead to greater or lesser interest.

Finally, the authors have only considered the "positive" consequences of increased expectations in this research. However, it is also likely that heightened expectations 
due to indiscriminate inclusion of sex and violence in previews might have adverse outcomes. For example, if viewers have been disappointed or angered by unfulfilled expectations that arose due to a significant discrepancy between a preview and an actual movie, they might pay less attention to previews in the future because of decreased faith in the previews' accuracy in representing what the movie will actually feature. Therefore, future research would benefit from exploring both the positive and negative implications of heightened expectations resulting from the inclusion of sexuality and violence in motion picture promotion.

With these limitations in mind, the results of this research contribute to the literature concerning the role of sex and violence in affecting audiences' enjoyment of media entertainment. Furthermore, they lend support to speculations of prior content analytic studies that have implied that depictions of sex and violence are found frequently in promotional materials because they are believed to lead to increased excitement and interest in watching the full movie. Of course, these findings should not be interpreted as suggesting that the "selling" of violence is something to be celebrated. In fact, the use of violence and aggression as a means of marketing entertainment is fraught with a host of problems, including potential risks of increasing aggression, of exposing viewers' to materials that they may find distressing, and of contributing to desensitization, among others. As a result, regardless of whether or not violence is an effective selling tool, other means of selling entertainment that are similarly effective at increasing viewer interest and anticipated enjoyment are worthy of research attention.

\section{Notes}

\footnotetext{
${ }^{1}$ Data for six females and one male were excluded from the sample because they reported having seen the movie trailer employed in this study.

${ }^{2}$ Descriptive statistics for all of the variables in all of the cells in Study 1 and Study 2 are available from the author upon request. The number of males and females in each experimental condition were as follows: no sex or violence: males, 11 , females 15 ; sex only: males, 11 , females 18; violence only: males 11 , females 17 ; sex and violence: males 7 , females 18 . The proportion of males to females did not differ between experimental conditions, $\chi^{2}(d f=3)=1.26, p=.74$. Because the gender of the participant did not interact with the manipulated IVs, males' and females' responses are combined. Using Cohen's (1988) effect size estimates, this design with 108 participants and $p<$ .05 had power to detect moderate effect sizes (.15) of .98 (Faul \& Erdfelder, 1992).

${ }^{3}$ Foreign-language films were employed in both studies to decrease the probability that participants would have seen the films or the previews. Additionally, the previews for these films featured no dialogue between the characters, making editing of the materials straightforward and believable.

${ }^{4}$ Data for seven females and four males were excluded from the sample because they reported having seen the movie trailer employed in this study. Because no significant differences were observed between the two sample locations on any of the dependent variables examined in the study, data for the two samples were combined.

${ }^{5}$ The number of males and females in condition were as follows: no sex or violence: males, 10 , females 25 ; sex only: males, 11 , females 23 ; violence only: males 6 , females 29 ; sex and violence: males 8 , females 23 . The proportion of males to females did not differ between experimental conditions, $\chi^{2}(d f=3)=2.27, p=.52$. Because the gender of the participant did not inter-
} 
act with the manipulated IVs, males' and females responses are combined. Using Cohen's (1988) effect size estimates, this design with 135 participants and $p<.05$ had power to detect moderate effect sizes (.15) of .99 (Faul \& Erdfelder, 1992).

\section{References}

Aluja-Fabregat, A. (2000). Personality and curiosity about TV and films violence in adolescents. Personality and Individual Differences, 29, 379-392.

Arbuckle, J. L. (1996). Amos users' guide, version 3.6. Chicago, IL: SPSS.

Bandura, A. (1983). Psychological mechanism of aggression. In R. G. Green \& E. I. Donnerstein (Eds.), Aggression: Theoretical and empirical reviews (Vol. 1, pp. 1-40). New York: Academic Press.

Berry, M., Gray, T., \& Donnerstein, E. (1999). Cutting film violence: Effects on perceptions, enjoyment, and arousal. The Journal of Social Psychology, 139, 567-582.

Bryant, J. (1989). Viewers' enjoyment of televised sports violence. In L. A. Wenner (Ed.), Media, sports, \& society (pp. 270-289). Newbury Park, CA: Sage.

Bryant, J., \& Miron, D. (2002). Entertainment as media effect. In J. Bryant \& D. Zillmann (Eds.), Media effects: Advances in theory and research (2nd ed., pp. 549-582). Mahwah, NJ: Lawrence Erlbaum Associates, Inc.

Bryant, J., \& Miron, D. (2003). Excitation-transfer theory and three-factor theory of emotion. In J. Bryant, D. Roskos-Ewoldsen, \& J. Cantor (Eds.), Communication and emotion: Essays in honor of Dolf Zillmann (pp. 31-59). Mahwah, NJ: Lawrence Erlbaum Associates, Inc.

Byrne, B. M. (2001). Structural equation modeling with AMOS: Basic concepts, applications, and programming. Mahwah, NJ: Lawrence Erlbaum Associates, Inc.

Cantor, J. R., Bryant, J., \& Zillmann, D. (1974). Enhancement of humor appreciation by transferred excitation. Journal of Personality and Social Psychology, 30, 812-821.

Cantor, J. R., \& Zillmann, D. (1973). The effect of affective state and emotional arousal on music appreciation. The Journal of General Psychology, 89, 97-108.

Cantor, J. R., Zillmann, D., \& Bryant, J. (1975). Enhancement of experienced sexual arousal in response to erotic stimuli through misattribution of unrelated residual excitation. Journal of Personality and Social Psychology, 32, 69-75.

Cohen, J. (1988). Statistical power analysis for the behavioral sciences (2nd ed.). Hillsdale, NJ: Lawrence Erlbaum Associates, Inc.

Cowan, G., \& O'Brien, M. (1990). Gender and survival vs. death in slasher films: A content analysis. Sex Roles, 23, 187-196.

Faber, R. J., \& O'Guinn, T. C. (1984). Effect of media advertising and other sources on movie selection. Journalism Quarterly, 61, 371-377.

Faul, F., \& Erdfelder, E. (1992). GPOWER: A prior, post-hoc, and compromise power analysis for MS-DOS. Bonn, FRG: Bonn University, Department of Psychology.

Federal Trade Commission. (2000). Marketing violent entertainment to children: A review of self-regulation and industry practices in the motion picture, music recording \& electronic game industries. Retrieved September 12, 2000, from http://www.ftc.gov/

Feshback, S., \& Singer, R. D. (1971). Television and aggression. San Francisco: Jossey-Bass.

Gerbner, G. (1999). The stories we tell. Peace Review, 11(1), 9-16.

Goldstein, J. H. (1986). Aggression and crimes of violence (2nd ed.). New York: Oxford University Press.

Hansen, C. H., \& Hansen, R. D. (1990). The influence of sex and violence on the appeal of rock music videos. Communication Research, 17, 212-234.

Jo, E., \& Berkowitz, L. (1994). A priming effect analysis of media influences: An update. In J. Bryant \& D. Zillmann (Eds.), Media effects: Advances in theory and research (pp. 43-60). Hillsdale, NJ: Lawrence Erlbaum Associates, Inc. 
King, C. M. (2000). Effects of humorous heroes and villains in violent action films. Journal of Communication, 50, 5-24.

King, C. M. (2003). Humor and mirth. In J. Bryant, D. Roskos-Ewoldsen, \& J. Cantor (Eds.), Communication and emotion: Essays in honor of Dolf Zillmann (pp. 349-378). Mahwah, NJ: Lawrence Erlbaum Associates, Inc.

Linz, D., \& Donnerstein, E. (1994). Sex and violence in slasher films: A reinterpretation. Journal of Broadcasting \& Electronic Media, 38, 243-246.

Maruyama, G. (1997). Basics of structural equation modeling. Thousand Oaks, CA: Sage Publications.

Mattes, J., \& Cantor, J. (1982). Enhancing responses to television advertisements via the transfer of residual arousal from prior programming. Journal of Broadasting, 26, 553-566.

MPAA Research Development. (2005). 2004 US economic review. Retrieved July 9, 2005, from http://www.mpaa.org/useconomicreview/

Oliver, M. B. (1993). Adolescents' enjoyment of graphic horror: Effects of viewers' attitudes and portrayals of victim. Communication Research, 20,30-50.

Oliver, M. B. (1994). Contributions of sexual portrayals to viewers' responses to graphic horror. Journal of Broadcasting \& Electronic Media, 38, 1-17.

Oliver, M. B., \& Kalyanaraman, S. (2002). Appropriate for all viewing audiences? An examination of violent and sexual portrayals in movie previews featured on video rentals. Journal of Broadcasting \& Electronic Media, 46, 283-299.

Potter, W. J., Pashupati, K., Pekurny, R. G., Hoffman, E., \& Davis, K. (2002). Perceptions of television: A schema. Media Psychology, 4, 27-50.

Potter, W. J., \& Warren, R. (1998). Humor as camouflage of televised violence. Journal of Communication, 48(2), 40-57.

Raney, A. A. (2003). Dispositon-based theories of enjoyment. In J. Bryant, D. Roskos-Ewoldsen, \& J. Cantor (Eds.), Communication and emotion: Essays in honor of Dolf Zillmann (pp. 61-84). Mahwah, NJ: Lawrence Erlbaum Associates, Inc.

Raney, A. A., \& Bryant, J. (2002). Moral judgment and crime drama: An integrated theory of enjoyment. Journal of Communication, 52, 402-415.

Roskos-Ewoldsen, D. R., Roskos-Ewoldsen, B., \& Carpentier, F. R. D. (2002). Media priming: A synthesis. In J. Bryant \& D. Zillmann (Eds.), Media effects (2nd ed., pp. 69-95). Mahwah, NJ: Lawrence Erlbaum, Inc.

Schumacker, R. E., \& Lomax, R. G. (1996). A beginner's guide to structural equation modeling. Mahwah, NJ: Lawrence Erlbaum Associates, Inc.

Segrin, C., \& Nabi, R. L. (2002). Does television viewing cultivate unrealistic expectations about marriage? Journal of Communication, 52, 247-263.

Sparks, G. G., Sherry, J., \& Lubsen, G. (2005). The appeal of media violence in a full-length motion picture: An experimental investigation. Communication Reports, 18, 21-30.

Streisand, B. (1999, June 14). Lawyers, guns, money. U. S. News \& World Report, 56-57.

Zillmann, D. (1971). Excitation transfer in communication-mediated aggressive behavior. Journal of Experimental Social Psychology, 7, 419-434.

Zillmann, D. (1980). Anatomy of suspense. In P. Tannenbaum (Ed.), The entertainment functions of television (pp. 133-163). Hillsdale, NJ: Lawrence Erlbaum Associates, Inc.

Zillmann, D. (1984). Connections between sex and aggression. Hillsdale, NJ: Lawrence Erlbaum Associations, Inc.

Zillmann, D. (1996). The psychology of suspense in dramatic exposition. In P. Vorderer, H. J. Wulff \& M. Friedrichsen (Eds.), Suspense: Conceptualizations, theoretical analyses, and empirical explorations (pp. 199-231). Mahwah, NJ: Lawrence Erlbaum Associates, Inc.

Zillmann, D. (1998). Connections between sexuality and aggression (2nd ed.). Mahwah, NJ: Lawrence Erlbaum Associates, Inc.

Zillmann, D. (2000). Humor and comedy. In D. Zillmann \& P. Vorderer (Eds.), Media entertainment: The psychology of its appeal. (pp. 37-57). Mahwah, NJ: Lawrence Erlbaum Associates, Inc. 
Zillmann, D., \& Bryant, J. (1991). Responding to comedy: The sense and nonsense in humor. In J. Bryant \& D. Zillman (Eds.), Responding to the screen: Reception and reaction processes. Hillsdale, NJ: Lawrence Erlbaum Associates, Inc.

Zillmann, D., \& Bryant, J. (1994). Entertainment as media effect. In J. Bryant \& D. Zillmann (Eds.), Media effects: Advances in theory and research (pp. 437-461). Hillsdale, NJ: Lawrence Erlbaum Associates, Inc.

Zillmann, D., Bryant, J., \& Sapolsky, B. S. (1989). Enjoyment from sports spectatorship. In J. H. Goldstein (Ed.), Sports, games, and play: Social and psychological viewpoints (2nd ed., pp. 241-278). Hillsdale, NJ: Lawrence Erlbaum Associates, Inc.

Zillmann, D., \& Cantor, J. R. (1977). Affective responses to the emotions of a protagonist. Journal of Experimental Social Psychology, 13, 155-165.

Zillmann, D., Hay, T. A., \& Bryant, J. (1975). The effect of suspense and its resolution on the appreciation of dramatic presentations. Journal of Research in Personality, 9, 307-323.

Zillmann, D., \& Mundorf, N. (1987). Image effects in the appreciation of video rock. Communication Research, 14, 316-334.

Zillmann, D., Taylor, K., \& Lewis, K. (1998). News as nonfiction theater: How dispositions toward the public cast of characters affect reactions. Journal of Broadcasting \& Electronic Media, 42, 153-169.

Zuckerman, M., \& Litle, P. (1986). Personality and curiosity about morbid and sexual events. Personality and Individual Differences, 7, 49-56. 